\title{
Predictors for the recurrent febrile seizures after the first complex febrile seizures
}

\author{
Conny Tanjung, Irawan Mangunatmadja, Sudigdo Sastroasmoro, I. Budiman
}

\begin{abstract}
Background Complex febrile seizures (CFS) have been shown to be related to recurrence and epilepsy. Many studies were done to determine the predictors of recurrence in both simple and complex febrile seizures. To our knowledge until now there is no published data that specially looks for predictors of recurrence after a first CFS.

Objective To find out clinical and demographical characteristics of a first CFS and to define the predictors for the recurrent febrile seizures.

Methods Prospective survival analysis study was done in children with first CFS who visited Cipto Mangunkusumo Hospital, Jakarta, over 14 months periods. The predictors for development of recurrence were analyzed by SPSS for Windows 11.5 using Kaplan-Meier test and Cox regression model with a level of significance $<0.05$.

Results There were 62 subjects completed this study. Male-tofemale ratio was 1.4:1. The mean age at onset was 18.2 months. Recurrence occurred in 9 subjects (14.5\%). Body temperature between $38-38.5^{\circ} \mathrm{C}$ ( 7 of 26 subjects, $\mathrm{P}=0.02$ ), upper motor neuron type of delayed development ( 3 of 7 subjects, $P=0.03$ ), and epileptic history in the family $(2$ of 2 subjects, $P<0.05$ ) were associated with recurrence in bivariate analysis. In multivariate analysis only body temperature between $38-38.5^{\circ} \mathrm{C}(\mathrm{HR} 1.6,95 \% \mathrm{Cl}$ $1.0 ; 23.9)$ and epileptic history in the family (HR 16.9, $95 \% \mathrm{Cl}$ $2.8 ; 101.4)$ were identified as predictors.

Conclusion Low body temperature at the first seizures and epileptic history in the family were independent predictors for the recurrence after a first CFS [Paediatr Indones 2006;46:204-208].
\end{abstract}

Keywords: complex febrile seizures, prognosis, pre-

dictors, recurrence
$\mathrm{F}$

ebrile seizures are the most common type of seizures in childhood, occurring in 2 to $5 \%$ of children. ${ }^{1,2}$ According to International League Against Epilepsy, febrile seizure is described as a seizure in association with a febrile illness in the absence of central nervous system infection or acute electrolyte imbalance in children older than 1 month of age without prior non-febrile seizures. $^{3}$ It can be broadly classified into two groups those are simple febrile seizures (SFS) and complex febrile seizures (CFS). ${ }^{4}$ Among those who develop febrile seizures, up to $27-37 \%$ of them would have CFS. A CFS is defined as febrile seizures with one or more of the following: 15 minutes or more in duration, more than one seizure in 24 hours or focal features. CFS had been shown to be related to recurrence and subsequent epilepsy. ${ }^{5-10}$

With these implications in mind, it is important for us to identify the predictors for the recurrence after the first CFS. To our knowledge until now there is no data that specially look for the predictors of recurrence after the first CFS. As a first step, this study was

From the Department of Child Health, Medical School, University of Indonesia, Jakarta, Indonesia.

Reprint requests to: Conny Tanjung, MD, Department of Child Health, Medical School, University of Indonesia, Cipto Mangunkusumo Hospital, Jl. Salemba Raya 6, Jakarta, Indonesia. Tel. 62-21-3907742. Fax. 62-213907743. Email: tanjungcon@yahoo.com. 
set to find out clinical and demographical characteristics of the first CFS and to define predictors for the recurrence.

\section{Methods}

A prospective survival analysis study was carried out on all children with the first CFS who visited outpatient clinics or emergency unit at the Department of Child Health, Medical School, University of Indonesia, Cipto Mangunkusumo Hospital, Jakarta, between February 2004 and April 2005. This study was approved by the Committee for Medical Research Ethics of Medical School, University of Indonesia. Sample size was estimated based on the rule of thumb, wherein the total samples were needed 10-50 times the number of predictors. ${ }^{10}$ Inclusion criteria were all children with the first CFS, age 3 months to 5 years, and agreed to participate in this study. Subjects who suffered from dehydration, got head injury during the study, or received daily anticonvulsant therapy after the first CFS were excluded. Home visit or interview by telephone was done on the first month after CFS and every three months there after to ascertain the occurrence of further febrile seizures.

Bivariate and Cox regression analysis, and calculation of hazard ratio (HR) were performed to correlate six predictors to the recurrent febrile seizures (RFS). All statistic procedures were done on SPSS 11.5 for Windows program.

\section{Results}

Median follow-up was 12.2 months (95\% CI 11.1 months; 13.3 months). Cumulative survival rate was $79 \%$. Most of the recurrences (6 from 9 cases) occurred in the first three months (Figure 1).

There were 62 subjects involved in this study; none of them were lost to follow-up. There were 36 (58\%) males and 26 (42\%) females with the ratio of males and females was 1.4:1. Their ages ranged from 3 to 53 months with a mean of 18.2 months. Nineteen subjects had suffered from SFS.

Diagnosis of CFS in this study was primarily based on the multiple $(>1)$ febrile seizures within 24 hours (55 subjects). Five (3\%) subjects had focal sei-

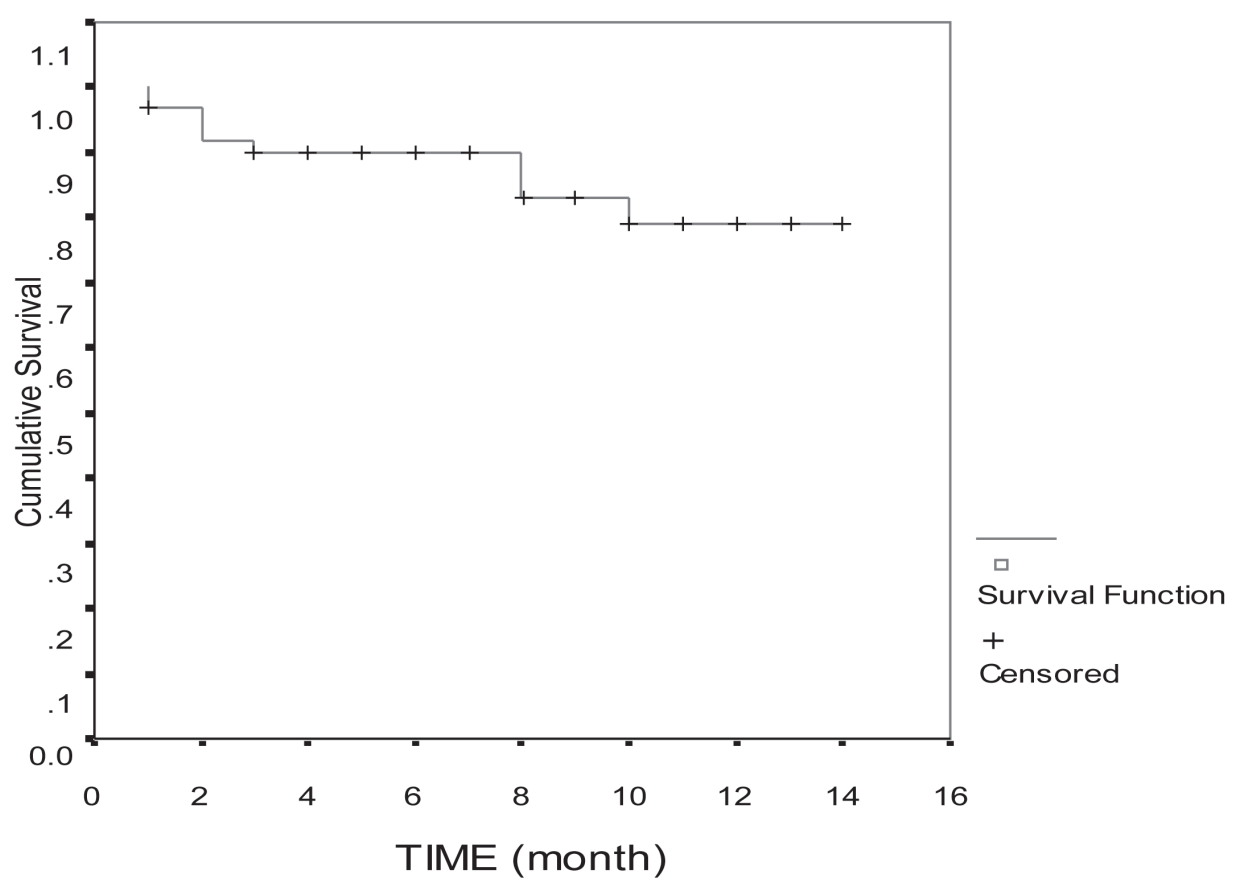

Figure 1. Cumulative survival of 62 subjects With first CFS. 
zures, 9 (15\%) subjects had prolonged seizures lasting 15 minutes or more, and 7 (11\%) subjects had two complex features. Todd's paresis was found in $1 \mathrm{sub-}$ ject who suffered from focal and prolonged seizures. This patient made uneventful recovery in 48 hours. RFS occurred in 9 (14.5\%) subjects. These recurrences happened in the form of simple and complex form (Table 1). During the study no epileptic seizure was found.

Associations of the predictors with the RFS were analyzed by Kaplan-Meier methods and log-rank test (Table 2). From the survival analysis we knew that upper motor neuron (UMN) type of delayed development, body temperature between $38-38.5^{\circ} \mathrm{C}$ at first $\mathrm{CFS}$, and epileptic history in the family were strongly correlated with recurrences. Duration between fever to the occurrence of CFS were marginally correlated $(\mathrm{P}=0.06)$. We found no association among recurrence and family history of febrile seizures and the age of 24 months or less. In the multivariate Cox model evaluating those three factors, all except delayed development retained their significance. Low degree in the first CFS had hazard ratio 1.6 (95\% CI 1.0;23.9), whereas subjects with epileptic histories in the family had HR 16.9 (95\% CI 2.8;101.4).

\section{Discussion}

Febrile seizures are the most frequent convulsive disorders during childhood periods. ${ }^{1-2}$ This study showed that onset of CFS was more frequently found in the

Table 1. Characteristics of first CFS and RFS.

\begin{tabular}{|c|c|c|c|c|c|c|}
\hline \multirow{2}{*}{$\begin{array}{l}\text { Characteristic } \\
\text { First CFS }\end{array}$} & & \multirow{2}{*}{$\begin{array}{c}\text { No } \\
\text { recurrence }\end{array}$} & \multicolumn{3}{|c|}{ Presence of recurrence } & \multirow[b]{2}{*}{ Multiple } \\
\hline & & & SFS & $>15$ min. & Focal & \\
\hline \multicolumn{7}{|l|}{ Duration } \\
\hline$<15$ minutes & 53 & 45 & 4 & 1 & 1 & 3 \\
\hline$=15$ minutes & 9 & 8 & 1 & 0 & 0 & 0 \\
\hline \multicolumn{7}{|l|}{ Type of seizure } \\
\hline General & 57 & 49 & 5 & 1 & 0 & 3 \\
\hline Focal & 5 & 4 & 0 & 0 & 1 & 0 \\
\hline \multicolumn{7}{|l|}{ Multiple } \\
\hline Yes & 55 & 48 & 4 & 1 & 0 & 3 \\
\hline No & 7 & 5 & 1 & 0 & 1 & 0 \\
\hline
\end{tabular}

$\mathrm{CFS}=$ complex febrile seizure; SFS=simple febrile seizure; RFS=recurrent febrile seizures.

Table 2. Analysis of predictors to eVent free survival using Kaplan-Meier methods and log-Rank test.

\begin{tabular}{|c|c|c|c|c|c|}
\hline Independent variable & $\begin{array}{c}\text { Number } \\
\text { of subjects } \\
n(\%)\end{array}$ & $\begin{array}{c}\text { Censored } \\
\text { subjects } \\
\text { n (\%) }\end{array}$ & $\begin{array}{c}\text { Number of } \\
\text { event } \\
n(\%)\end{array}$ & $\begin{array}{c}\text { Cumulative } \\
\text { survival } \\
(95 \% \mathrm{CI})\end{array}$ & $\begin{array}{c}P \\
\text { (mo.) }\end{array}$ \\
\hline \multicolumn{6}{|l|}{ Age (month) } \\
\hline$\leq 24$ & 479760 & $38(81)$ & $9(19)$ & $10.3(13.0-14.6)$ & 0.09 \\
\hline$>24$ & $15(24)$ & $15(100)$ & $0(0)$ & & \\
\hline \multicolumn{6}{|l|}{ Temperature at $\mathrm{CFS}\left({ }^{\circ} \mathrm{C}\right)$} \\
\hline $38.0-38.5$ & $26(42)$ & $19(73)$ & $7(27)$ & $10.1(8.3-11.9)$ & 0.02 \\
\hline$\geq 38.6$ & $36(58)$ & $34(94)$ & $2(6)$ & $13.3(12.4-14.2)$ & \\
\hline \multicolumn{6}{|c|}{ UMN type of delayed development } \\
\hline Yes & $7(11)$ & $4(57)$ & $3(43)$ & $8.2(4.9-11.5)$ & 0.03 \\
\hline No & $55(89)$ & $49(89)$ & $6(11)$ & $12.7(11.7-13.7)$ & \\
\hline \multicolumn{6}{|l|}{$\begin{array}{l}\text { Duration between } \\
\text { fever and seizures }\end{array}$} \\
\hline$\leq 24$ hours & $47(76)$ & $38(81)$ & $9(19)$ & $11.6(10.2-13.0)$ & 0.06 \\
\hline$>24$ hours & $15(24)$ & 15 (100) & $0(0)$ & & \\
\hline \multicolumn{6}{|c|}{ Family history of febrile seizures } \\
\hline Yes & $22(35)$ & $18(82)$ & $4(18)$ & $10.3(8.8-11.9)$ & 0.43 \\
\hline No & $40(65)$ & $35(87)$ & $5(13)$ & $12.5(11.2-13.7)$ & \\
\hline \multicolumn{6}{|l|}{ Epilepsy in the family } \\
\hline Yes & $2(3)$ & $0(0)$ & $2(100)$ & $2.0(2.0-2.0)$ & $<0.05$ \\
\hline No & $60(97)$ & $53(88)$ & $7(12)$ & $12.6(11.6-13.6)$ & \\
\hline
\end{tabular}


13-23 months groups. Males were more affected than females and the male-to-female ratio was 1.4:1. This result was consistent with studies of Bessiso et al, ${ }^{5}$ Verity et al, ${ }^{12}$ and Rosman et al. ${ }^{13}$ Family history of febrile seizures is unlikely to be associated with first CFS. These results were supported by the study of Ling ${ }^{14}$ and van Stuijvenberg et al. ${ }^{15}$

RFS could happen in the form of SFS and CFS. Most of them occurred in the first 3 months after the onset $(67 \%)$. Evita ${ }^{16}$ found that half of the recurrences occurred in 3 months after first febrile seizures, while another study stated that $50-75 \%$ recurrences occurred in the first year after the onset of seizures. ${ }^{17}$

The recurrence rates in this study were $14.5 \%$. Our finding was lower than that of other studies. Studies of the recurrence rates (both after SFS and CFS) in the third world are ranging from $21-29.3 \%$. In the west, however, recurrence rates are much more variable, ranging from $30-50 \% .{ }^{18}$ In the Berg series, 428 children with a first febrile seizure were followed up for an average of 29 months. They found the recurrence rate of $31.3 \%{ }^{8}$

The low recurrence rates in this study could be caused by short duration of the study or the effectiveness of the prophylactic therapy. The controversy about the effectiveness of oral and rectal diazepam still persists. Meta-analysis by Rantala et al ${ }^{19}$ showed that intermittent diazepam had no prophylactic effect on decreasing recurrences, but this meta-analysis is still on debate.

When studying the predictors for recurrence, we found that children whose body temperature was $38-38.5^{\circ} \mathrm{C}$ at the onset of the seizures were more likely to have RFS (7 of 9 subjects). No recurrence was found in subjects with body temperature of more than $40^{\circ} \mathrm{C}$ at the onset of CFS. Association between RFS and a relatively low fever at the time of the initial CFS had been reported by other studies. ${ }^{9,20}$ This was consistent with a threshold model, i.e. children whose seizures occurred with relatively low fever required less provocation to have a seizure than those whose initial seizures occurred at higher temperatures. $^{8}$

Family history of epilepsy in a first-degree relative was found in two subjects and both of them experienced recurrences. HR for this predictors is 16.9 (95\% CI 2.8;101.4). In a pooled analysis of five studies, Offringa et all found the HR of 1.34 (95\%CI
$1.04 ; 1.73)$ for the subjects with epileptic history in the family. Study of 96 children with a first febrile seizure in Jakarta, found one RFS from five subjects with epileptic history in their families. ${ }^{16}$

Our data showed that delayed development was associated with RFS in bivariate analysis. UMN type of delayed development was found in seven subjects with first CFS. Recurrence occurred in three of those subjects $(\mathrm{P}=0.03)$. This association did not occur in multivariate analysis with Cox regression model. This finding is consistent with Berg et al. ${ }^{8}$ They stated that the designation of "abnormal" in their studies were not based on an evaluation by a neurologist or a standardized evaluation with a special research protocol, so the lack of association in their studies should not be used to contradict positive findings of other studies. Study in middle east found no association between delayed development with RFS $(\mathrm{P}=0.81),{ }^{15}$ while study in Jakarta found 2 RFS in 15 subjects with neurodevelopmental abnormality. ${ }^{16}$

Age was the best-established risk factors and it had been reported in virtually most studies of RFS. Febrile seizures were believed to occur during a period when the brain, for developmental reasons, is particularly susceptible to having seizures. The earlier a child had his or her febrile seizures, the longer he or she was in at risk of recurrence. ${ }^{8}$ In our study, 8 out of 9 subjects that experienced RFS were in the group of 13-23 months. No significant association in this study could be caused by small sample size. Berg et $a l^{8}$ stated that age below 12 months was associated with a RFS, while 2 other studies found in subjects below 2 years-old.

As with age, family history of febrile seizures was not statistically significant at the bivariate level of analysis in our study $(\mathrm{P}=0.43)$. This finding is consistent with two other studies. ${ }^{16,18}$ Meta-analysis by Offringa et al ${ }^{20}$ found an overall RFS of $43 \%$ in children who had a positive family history (first degree relative) as opposed to a $32 \%$ recurrences in those without a positive family history. Berg et al ${ }^{8}$ compared the risk of RFS at one year of age in children with a positive family history and those without. At one year, the risk of recurrence was 36\% (95\% CI) for those with a positive family history versus 20\% (95\% CI) for those without.

We also evaluated the association of recurrence with duration of recognized fever before the CFS. We 
found that all recurrences occurred in subjects with fever lasting 1-24 hours. The marginal difference $(\mathrm{P}=0.06)$ between survival of subjects with short duration of recognized fever compared to the longer duration could be caused by small sample in this study. Berg et $a l^{8}$ found that relative risk of recurrence decreased as the duration got longer (RR 0.4, 95\% CI $0.35 ; 0.66)$. Similar results found in Jakarta study. ${ }^{16}$ Out of 41 subjects with duration of more than $>16$ hours, only 3 subjects experienced recurrences (7.3\%), whereas with duration of $\leq 16$ hours the recurrences was $9.8 \%$.

This study has several limitations. Among of these were the short duration of the study, the small sample size, and noncompliance of some subjects (4 for 9 subjects) to use the intermittent anticonvulsant therapy given to them.

We conclude that low temperature at the first CFS and epileptic history in the family were independent predictors factors for the occurrence of the RFS.

\section{References}

1. Hirtz DG. Febrile seizure. Pediatr Rev 1997;18:5-9.

2. Rosman NP. Febrile convulsions. In: Mackowiak PA, editor. Fever: Basic mechanism and management. 2nd edition. Philadelphia: Lippincott; 1997. p. 267-77.

3. Commission on epidemiology and prognosis, International League Against Epilepsy. Guidelines for epidemiologic studies on epilepsy. Epilepsia 1993;34:592-6.

4. American Academy of Pediatrics. Committee on quality improvement, subcommittee on febrile seizures. Practice parameter: Long term treatment of the child with simple febrile seizures. Pediatrics 1999;103:1307-9.

5. Bessisso MS, Elsaid MF, Almula NA, Kadomi NK, Zeidan SH, Azzam SB, et al. Recurrence risk after a first febrile convulsion. Saudi Med J 2001;22:254-8.

6. Verity CM. Do seizures damage the brain? The epidemiological evidence. Arch Dis Child 1998;78:78-84.

7. Shinnar S. Febrile seizures. In: Swaiman KF, Ashwal S, editors. Pediatric neurology: Principles \& practice. 3rd edition. St. Louis: Mosby; 1999. p. 676-82.

8. Berg AT, Shinnar S. Complex febrile seizures. Epilepsia 1996;37:126-33.
9. Van Stuijvenberg M, Steyerberg EW, Derksen-Lubsen G, Moll HA. Temperature, age, and recurrences of febrile seizure. Arch Pediatr Adolesc Med 1998; 152:1170-5.

10. Berg AT, Shinnar S, Levy SR, Testa FM. Childhoodonset epilepsy with and without preceding febrile seizures. Neurology 1999;53:1742-8.

11. Madiyono B, Moeslichan S, Sastroasmoro S, Budiman I, Purwanto SH. Perkiraan besar sampel. In: Sastroasmoro S, Ismael S, editors. Dasar-dasar metodologi penelitian klinis. Jakarta: CV Sagung Seto; 2002. p. 259-87.

12. Verity CM, Greenwood R, Golding J. Long-term intellectual and behavioral outcomes of children with febrile convulsions. N Engl J Med 1998;338:1723-8.

13. Rosman NP, Colton T, Labazzo J. A controlled trial of diazepam administered during febrile illnesses to prevent recurrence of febrile seizures. N Engl J Med 1993;329:79-84.

14. Ling SG. Clinical characteristics and risk factors for a complex first febrile convulsion. Singapore Med J 2001;42:264-7.

15. Van Stuijvenberg M, Beijeren E, Wils NH, DerksenLubsen G, Duijn CM, Moll HA. Characteristics of the initial seizure in familial febrile seizures. Arch Dis Child 1999;80:178-80.

16. Evita. Berulangnya kejang demam pada penderita kejang demam pertama [thesis]. Jakarta: University of Indonesia; 1992.

17. Nelson KB, Ellenberg JH. Prognosis in children with febrile seizures. Pediatrics 1978;61:720-7.

18. Habib Z, Akram S, Ibrahim S, Hasan B. Febrile seizures: Factors affecting risk of recurrence in Pakistani children presenting at the Aga Khan University Hospital. J Pak Med Assoc 2003;53:11-7.

19. Rantala H, Tarkka R, Uhari M. A meta-analytic review of the preventive treatment of recurrences of febrile seizures. J Pediatr 1997;131:922-6.

20. Offringa M, Bossuyt PMM, Lubsen J, Ellenberg JH, Nelson KB, Knudsen FU, et al. Risk factors for seizure recurrence in children with febrile seizures: A pooled analysis of individual patient data from five studies. J Pediatr 1994;124:574-84.

21. Tarkka R, Rantala H, Uhari M, Pokka T. Risk of recurrence and outcome after the first febrile seizure. Pediatr Neurol 1998;18:218-20. 